\title{
A Novel a-Fe203/TiO2 heterostructured nanocomposite with Enhanced Visible-light Photocatalytic Performance for Degradation of Organic Pollutant
}

\section{Kavitha S}

Government Arts college

\section{Ranjith R}

Periyar University

Jayamani N ( $\nabla$ jayamaniphysics@gmail.com )

Government Arts college https://orcid.org/0000-0002-5850-8849

\section{Research Article}

Keywords: TiO2/a-Fe2O3, Visible-light, Photocatalysts, Methylene Blue, Dye degradation, Recycling stability, Hydroxyl radicals

Posted Date: February 16th, 2021

DOl: https://doi.org/10.21203/rs.3.rs-198078/v1

License: (c) (1) This work is licensed under a Creative Commons Attribution 4.0 International License.

Read Full License 


\section{Abstract}

A novel heterostructured catalyst of $\mathrm{TiO}_{2} / \mathrm{a}-\mathrm{Fe}_{2} \mathrm{O}_{3}$ nanocomposite (NC) was successfully fabricated by the facile hydrothermal method and mutual ultrasonication. To characterize the as-fabricated photocatalysts (PCs) by PXRD, FT-IR, HRSEM, HRTEM, UV-Vis DRS absorption, and PL spectra analysis relatively. The optical absorbance of $\mathrm{TiO}_{2} / \mathrm{a}-\mathrm{Fe}_{2} \mathrm{O}_{3} \mathrm{NC}$ was measured in the wavelength range from $320-800 \mathrm{~nm}$ and the optical bandgap $\left(\mathrm{E}_{\mathrm{g}}\right)$ was declined from 3.21 to $2.72 \mathrm{eV}$. The photocatalytic efficiency of $\mathrm{TiO}_{2} / \mathrm{a}-\mathrm{Fe}_{2} \mathrm{O}_{3}$ composite catalyst was assayed in the degradation of aqueous methylene blue (MB) dye in the visible-light influence. The results showed that the heterostructured a- $\mathrm{Fe}_{2} \mathrm{O}_{3} / \mathrm{TiO}_{2}$ catalyst was much faster and higher removal efficiency of MB dye $(\sim 92.7 \%)$ than the other photocatalytic degradation of pristine $\mathrm{TiO}_{2}(33 \%)$ and a- $\mathrm{Fe}_{2} \mathrm{O}_{3}(47.3 \%)$ in $100 \mathrm{~min}$. The enriched photocatalytic efficiency also accredited to enlarged energy harvesting ability, enhanced in the widened absorption in visible-light region, synergistic effects produced a great number of photo-produced electronhole $\left(\mathrm{e}^{-} / \mathrm{h}^{+}\right)$separation, stronger oxidation ability by hydroxyl radicals $\left({ }^{-} \mathrm{OH}\right.$.) via the interfaces of $\mathrm{a}-\mathrm{Fe}_{2} \mathrm{O}_{3}$ dispersed $\mathrm{TiO}_{2}$ heterojunction. All these outcomes specify that the highly stable and recyclable $\mathrm{TiO}_{2} /$ $\mathrm{a}-\mathrm{Fe}_{2} \mathrm{O}_{3}$ photocatalyst has the possibility of the practical application for wastewater treatment.

\section{Introduction}

To meet the shortage in water supply worldwide and improving the environmental pollution, the elimination of several impurities from adequate water has major pervasive problem worldwide with widespread concerned. Nowadays the rapid industrialization of modern society exclusively in the developing countries, organic dyes are widely used in paper, leather, textile, pigment, cosmetic, food, and drug manufacturing [1-3]. Besides, the industrial and sanitary sewage comprises dyes cause water contamination as serious health problems and they are hazardous effects toward aquatic organisms, plants, humans, animals and aquatic ecosystem. Therefore, it is urgent to eliminate organic dyes from wastewaters. From former few decades, various techniques have been adopted to remove the dyecontaining waters such as advanced oxidation processes (AOPs), physical adsorption, ozonation, photolysis and biological decomposition [3, 4]. Among them, semiconductors (SCs) heterogeneous photocatalytic AOPs decomposition has been expected to be effective strategies for used by many researchers since of its high degradation/mineralization efficiency to remove organic pollutants from wastewater due to the reactive- $\mathrm{OH} \bullet$, also low toxicity, low-cost, and ability to function under ambient settings [5].

Among various semiconductor photocatalysts (PCs), the well-known Titania $\left(\mathrm{TiO}_{2}\right)$ has attracted extensive courtesy owed to their preponderant potential features such as low-cost, non-toxicity, high photo-stability, fine electronic assets, great photochemical corrosive resistance, strong oxidizing power and photocatalytic movement [6-8]. This is based on the absorption of a photon of appropriate energy $(\sim 3.2 \mathrm{eV})$ and the creation of charge carriers (photo-electrons $\left(\mathrm{e}^{-}\right)$and photo-holes $\left(\mathrm{h}^{+}\right)$) that could oxidize organic pollutants into $\mathrm{CO}_{2}$ and $\mathrm{H}_{2} \mathrm{O}$. However, the practical application of $\mathrm{TiO}_{2}$ catalyst is 
hindered by the serious agglomeration of $\mathrm{TiO}_{2}$ nanoparticles (NPS) and the quick recombination of the photo-produced $\left(\mathrm{e}^{-} / \mathrm{h}^{+}\right)$pairs $[9,10]$. Moreover, the wide bandgap of $\mathrm{TiO}_{2}$ limits its photocatalytic property in the ultraviolet (UV) region, which accounts for $3-5 \%$ of the total solar-light proportion spectrum. Since utilizing the visible-light is much more abundant $(\sim 43 \%)$ than UV light in the solar source, hence its efforts to synthesize efficient visible-light-responsive $\mathrm{TiO}_{2}$-based PCs are highly desired [11]. Several methods have been employed for enlightening the photocatalytic activity, the tremendous efforts are going to develop visible-light-driven (VLD) semiconductor PCs with heterojunction architecture for the $\mathrm{TiO}_{2}$ PCs were coupled with various narrower bandgap SCs, such as $\mathrm{CeO}_{2}, \mathrm{WO}_{3}, \mathrm{~g}-\mathrm{C}_{3} \mathrm{~N}_{4}, \mathrm{MoS}_{2}, \mathrm{GO}, \mathrm{Cu}_{2} \mathrm{O}$, $\mathrm{Fe}_{2} \mathrm{O}_{3}$ and $\mathrm{CdS}[11-16]$.

Among diverse metal-oxides (MOs) semiconductor PCs, hematite $\left(\mathrm{a}-\mathrm{Fe}_{2} \mathrm{O}_{3}\right)$ is kind of typical n-type SCs also facilitate the promising photocatalytic water splitting and water treatment applications. Because of its narrow bandgap ( 2.0-2.2 eV), which exhibits excellent properties such as non-toxicity, environmentally friendly, natural abundance, superior chemical steadiness, high corrosion resistance, good conductivity, better visible-light fascination ability and solid oxidation power [17]. To resolve this inadequacy, it is an attractive route to organize the effective PCs by incorporating magnetic a-Fe $\mathrm{O}_{3}$, which not only prevents the agglomeration of other NPs during recovery but also deals the synergetic enrichment of catalytic activity to some extent by forming a hybrid structure [18]. Nevertheless, the photoproduced $\left(\mathrm{e}^{-} / \mathrm{h}^{+}\right)$pairs in the valence band (VB) and conduction band (CB) of $\mathrm{a}-\mathrm{Fe}_{2} \mathrm{O}_{3}$ are easier to be excited under visible-light exposure [19]. Besides, the coupling between $\mathrm{a}-\mathrm{Fe}_{2} \mathrm{O}_{3}$ and $\mathrm{TiO}_{2} \mathrm{NPs}$ forms most promising nanostructures (NSs) could support to the spatial electron $\left(\mathrm{e}^{-}\right)$transfer, preventing the recombination of $\mathrm{e}^{-} / \mathrm{h}^{+}$pairs and supplying more reaction active sites for widely improve the photocatalytic performance and recycling uses. Therefore, band bending might occur that the $\mathrm{CB}$ edge of $\mathrm{a}-\mathrm{Fe}_{2} \mathrm{O}_{3}$ is higher than that of $\mathrm{TiO}_{2}$ when their Fermi levels are equalized [17]. As well, $\mathrm{a}-\mathrm{Fe}_{2} \mathrm{O}_{3}$ ions particularly adsorb on the negatively charged $\mathrm{TiO}_{2} \mathrm{NPs}$ by electrostatic dealings. Also, the modification of their band structures via unique properties of $\mathrm{a}-\mathrm{Fe}_{2} \mathrm{O}_{3}$ makes a suitable aspirant for coupling with $\mathrm{TiO}_{2}$ would progress a new energy-level mismatch for visible-light photocatalysis. Therefore, $\mathrm{a}-\mathrm{Fe}_{2} \mathrm{O}_{3}$ has been extensively used as combined for VLD $\mathrm{TiO}_{2}$-based PCs by the hydrothermal assisted technique with the ultrasonic wave's supports. Since, hydrothermal assisted precipitation has applied most effective route among various techniques, to fabricate the effectual NPs and nanocomposites (NCs) samples due to its high purity, simple preparation, stoichiometry control and homogeneous distribution of coupling components [20]. Fortunately, Magnetic PCs might be proficiently separated and reprocessed by applying an external magnetic field.

In this existent document, a novel $\mathrm{TiO}_{2} / \mathrm{a}-\mathrm{Fe}_{2} \mathrm{O}_{3}$ coupled heterogeneous photocatalyst were synthesized by facile hydrothermal assisted precipitation with then ultrasonic dispersion strategy. The as-fabricated NCs were characterized by various physicochemical analysis systems. Consequently, the effect of structural parameters, outstanding photocatalytic efficiency of MB dye decomposition under visible-light 
treatment and excellent reusability of the used catalyst. Also, an interrelated major photocatalytic mechanism was proposed systematically.

\section{Experimental}

\subsection{Materials and reagents}

Sodium Hydroxide ( $\mathrm{NaOH}$ ) was obtained from Pure Chem Chemical Co., India. Titanium (IV) isopropoxide (TTIP, Ti $\left(\mathrm{OC}_{4} \mathrm{H}_{9}\right)_{4} 98.5 \%$ ) was attained since Alfa Aesar Chemical Co., India. (( $\left.\mathrm{FeCl}_{3}, 6 \mathrm{H}_{2} \mathrm{O}\right), 99 \%$ ), Polyvinylpyrrolidone (PVP, $\left.\left.\left(\mathrm{C}_{6} \mathrm{H}_{9} \mathrm{NO}\right)_{n}\right) 98 \%\right)$, 2-propanol $\left(\mathrm{C}_{16} \mathrm{H}_{21} \mathrm{NO}_{2}, 98 \%\right)$ and Ethanol Absolute $\left(\mathrm{C}_{2} \mathrm{H}_{6} \mathrm{O}\right.$, $96 \%$ ), were attained from Merck Chemical Co., India. Entire chemicals were used here in analytical reagent (A.R) grade without auxiliary refinement, and reaction solutions were formed with high purity deionized (D.I.) water.

\subsection{Material synthesis}

The pristine $\mathrm{TiO}_{2}$ NPs was fabricated by facile sol-gel process. Initially, the typical $5 \mathrm{~mL}$ of TTIP was added into $30 \mathrm{~mL}$ of 2-propanol solution. Then, the $0.1 \mathrm{~g}$ of PVP mixed with $20 \mathrm{~mL}$ of D.I. water was openly added to the solution through magnetically stirred for $60^{\circ} \mathrm{C}$ at $4 \mathrm{~h}$, next it was chilled and washed numerous times. Finally, the harvested $\mathrm{TiO}_{2} \mathrm{NPs}$ was dried overnight, and it's also crushed gently with mortar to acquire $\mathrm{TiO}_{2} \mathrm{NPs}$ [21]. The a- $\mathrm{Fe}_{2} \mathrm{O}_{3} \mathrm{NPs}$ were prepared via the precipitation route. In a typical experiment, $0.1 \mathrm{M} \mathrm{FeCl}_{3} \cdot 6 \mathrm{H}_{2} \mathrm{O}$ and $0.1 \mathrm{~g}$ of PVP were dissolved in $100 \mathrm{~mL}$ of D.I. water and $50 \mathrm{~mL}$ of ethanol absolute solution composed under continuous vigorous stirring for $1 \mathrm{~h}$ at a temperature of 70 ${ }^{\circ} \mathrm{C}$. Next, the ammonia aqueous solution was slow added dropwise into beyond colloidal suspensions to adjust the $\mathrm{pH} \sim 11$ and subsequently aged at $60^{\circ} \mathrm{C}$. After naturally cooling at room temperature, the resultant dark red precipitates were obtained which were collected by centrifugation (3000 rpm), rinsed with D.I. water and ethanol to remove excess chlorine ions from the filtered material [22]. The obtained wet precipitous was then dried for $10 \mathrm{~h}$ at $80^{\circ} \mathrm{C}$ and then calcined in air at $750^{\circ} \mathrm{C}$ for $3 \mathrm{~h}$ to obtain $\mathrm{a}-\mathrm{Fe}_{2} \mathrm{O}_{3} \mathrm{NPs}$.

$\mathrm{TiO}_{2} / \mathrm{a}-\mathrm{Fe}_{2} \mathrm{O}_{3} \mathrm{NC}$ samples were also fabricated via the effective hydrothermal precipitation approach: Asfabricated $\mathrm{TiO}_{2}$ and of $\mathrm{a}-\mathrm{Fe}_{2} \mathrm{O}_{3} \mathrm{NPs}$ content were dispersed into ethanol and intensively sonicated for 30 min by probe ultrasonication. The resulting mixed suspension was after transferred into a $100 \mathrm{~mL}$ of Teflon-lined stainless steel autoclave and then finally treated at $150{ }^{\circ} \mathrm{C}$ for $5 \mathrm{~h}$ to attain $\mathrm{TiO}_{2} / \mathrm{a}-\mathrm{Fe}_{2} \mathrm{O}_{3}$ heterogeneous composite in powder form [23].

\subsection{Structural characterizations}

Powder X-ray diffraction (XRD) analysis was passed out to define the crystal structure and phase of the as-fabricated PCs by Rigaku Miniflex II X-ray diffractometer, which was a Cu Ka radiation $(\lambda=1.54056 \AA)$. Fourier-transform infrared (FT -IR) spectra were noted on a Perkin Elmer RX-1 spectrometer via a $\mathrm{KBr}$ 
pellet method in the ranges of $4000-400 \mathrm{~cm}^{-1}$ for exploring the functional features. To identify surface morphologies and elemental configuration (weight \%), High-resolution scanning electron microscope images, including Energy dispersive X-ray spectra (EDXS) were documented through HR-SEM; FEI Quanta FEG 200. The shape and deep microstructure were advance categorized by High-resolution Transmission electron microscopy (HRTEM) analysis consuming a JEOL/JEM 2100, operated at an accelerating voltage of $200 \mathrm{kV}$. UV-Vis diffuse reflectance spectroscopy (UV-Vis DRS) analysis was attained the optical absorption spectra on a UV2550; Shimadzu device. The room temperature photoluminescence (PL) spectral analysis was conceded out using a Perkin-Elmer-LS 100 by the excitation wavelength series on $\lambda_{\mathrm{ex}}=\sim 330 \mathrm{~nm}$.

\subsection{Photocatalytic activity}

The photocatalytic acts of as-fabricated catalysts were assessed by VLD photodegradation with $50 \mathrm{mg}$ of the as-fabricated PCs were dispersed into $20 \mathrm{ppm}$ of MB aqueous dye solution injected into a $100 \mathrm{~mL}$ on the cylindrical quartz reflux system. To realize adsorption-desorption ability in the dark with actively stirred for $30 \mathrm{~min}$. Then combined the decolourization performance scrutinized under the irradiation of visible-light and the $300 \mathrm{~W}$-Xe lamp furnished by a reflection cutoff filter $(\lambda>420 \mathrm{~nm})$ was resolute typically to prompt the photocatalytic response [24]. Every 20 minutes, to acquire nearly $2.0 \mathrm{~mL}$ of the liquid suspension was reserved out and centrifuged the pure solution was examined by UV-Vis spectra (Perkin Elmer-Lambda 35) at the utmost absorption band wavelength for MB ( 664 nm) [25]. The photodecomposition removal efficiency $\%$ of MB dye was intended by the equation; Efficiency $(\%)=\left(\mathrm{C}_{0^{-}}\right.$ $\mathrm{C}_{\mathrm{t}} / \mathrm{C}_{0} * 100$. Besides, the kinetic study of dye elimination enactment was deliberated agreeing to an equation of linear pseudo-first-order relation model, $-\mathrm{Ln}\left(\mathrm{C}_{0} / \mathrm{C}_{t}\right)=\mathrm{kt}$. Wherever $\mathrm{C}_{t}$ was the absorption found to $\mathrm{MB}$ dye in the preferred time intervals, $\mathrm{k}$ stands for the dye removal pseudo-first-order rate constant, $\mathrm{C}_{0}$ has the initial absorbance of the MB dye at $t=0 \mathrm{~min}$, and relative time $t$. For photocatalytic recycling trials, the investigational ailment was fixed as similar as aqueous MB photo-degradation format, and hence the catalysts have further washed, dried to succeeding reaction cycle [26]. The remaining concentration of aqueous MB dye was projected in each cycle for assessing the reusability of the asfabricated PCs.

\section{Results And Discussion}

Figure 1 illustrates the XRD pattern of as-fabricated pristine $\mathrm{TiO}_{2}, \mathrm{a}-\mathrm{Fe}_{2} \mathrm{O}_{3}$ and $\mathrm{TiO}_{2} / \mathrm{a}-\mathrm{Fe}_{2} \mathrm{O}_{3} \mathrm{NC}$ samples. Crystalline planes consistent to the peaks for $\mathrm{TiO}_{2}$ and $\mathrm{a}-\mathrm{Fe}_{2} \mathrm{O}_{3}$ were well-indexed in this Fig. 1 (A). Numerous characteristic crystalline peaks are sensed for pristine $\mathrm{TiO}_{2}$ sample at $2 \theta=25.2^{\circ}, 38.4^{\circ}, 48.2^{\circ}$, $53.9^{\circ}, 55.2^{\circ}$ and $62.8^{\circ}$ indexed to the (101), (112), (200), (105), (211) and (213) crystalline planes signifying the presence of prime $\mathrm{TiO}_{2}$ tetragonal anatase crystallization phase (JCPDS file no. 21-1272) individually $[18,27]$. Conversely, minor peaks are noticed at around $27.4^{\circ}$ owed to the presence of a slight portion of $\mathrm{TiO}_{2}$ rutile phase. Also, chief diffraction peaks at $24.3^{\circ}, 35.4^{\circ}, 40.7^{\circ}$ and $54.23^{\circ}$ could be consigned to (012), (110), (113) and (116) crystal planes in the best contract (JCPDS file no. 01-1053) 
with rhombohedral hematite $\mathrm{a}-\mathrm{Fe}_{2} \mathrm{O}_{3}$ phase relatively. Accordingly, the XRD outcomes exposed that there effectively formation of a- $\mathrm{Fe}_{2} \mathrm{O}_{3} \mathrm{NPs}$ on the $\mathrm{TiO}_{2}$ provision. No further impurity peaks are noticed, specifying the high phase pureness of $\mathrm{TiO}_{2} / \mathrm{a}-\mathrm{Fe}_{2} \mathrm{O}_{3}$ composite heterojunction has been fruitfully fabricated [28]. The average crystalline sizes of as-fabricated pristine $\mathrm{TiO}_{2}, \mathrm{a}-\mathrm{Fe}_{2} \mathrm{O}_{3}$ and $\mathrm{TiO}_{2} / \mathrm{a}-\mathrm{Fe}_{2} \mathrm{O}_{3}$ catalysts were intended by Scherrer equation [1] and the detected values are 31, 19 and $23.5 \mathrm{~nm}$ separately. Hence, it's due to the substantial interface among the anatase and rhombohedral crystallites phases of $\mathrm{TiO}_{2} / \mathrm{a}-\mathrm{Fe}_{2} \mathrm{O}_{3}$ composite and would stabilize the surfaces by precluding auxiliary evolution of crystallization.

The FT-IR spectra were employed to inspect the chemical bonding of the as-obtained NMs. Figure 2 displays the FT-IR spectra for as-fabricated pristine $\mathrm{TiO}_{2}, \mathrm{a}-\mathrm{Fe}_{2} \mathrm{O}_{3}$ and $\mathrm{TiO}_{2} / \mathrm{a}-\mathrm{Fe}_{2} \mathrm{O}_{3}$ composites. The wide and high-intensity absorption peaks regions supposed under $800 \mathrm{~cm}^{-1}$ (i.e.) 462,567 and $721 \mathrm{~cm}^{-1}$ could be consigned to the grouping of $\mathrm{Ti}-\mathrm{O}-\mathrm{Ti}$, $\mathrm{Ti}-\mathrm{O}$ bond bridging stretching vibrations, and $\mathrm{Fe}-\mathrm{O}$ asymmetric stretching, vibration kinds resulting from the chemical interface amid $\mathrm{TiO}_{2}$ and a- $\mathrm{Fe}_{2} \mathrm{O}_{3}$ crystalline nanostructures designating that the co-presence of $\mathrm{TiO}_{2}$ and $\mathrm{a}-\mathrm{Fe}_{2} \mathrm{O}_{3}$ in the heterojunction [29, 30]. However, $\mathrm{C}=\mathrm{O}$ and $\mathrm{C}-\mathrm{O}$ are widening vibration absorption bands performed at 1753 and $1045 \mathrm{~cm}^{-1}$ for almost atmospheric carbons in the FT-IR absorption spectra. The absorption peaks in the array of $2830-2980 \mathrm{~cm}^{-1}$ agree to $\mathrm{CH}$ vibrations. The typical extensive absorptive peak regions at 1632 and 3451 $\mathrm{cm}^{-1}$ are allotted to the $\mathrm{OH}$ bending and stretching vibrations appeared from free adsorbed water $\left(\mathrm{H}_{2} \mathrm{O}\right)$ molecules respectively [31].

Fig. 3 (a) exhibits the HRSEM image of pristine $\mathrm{TiO}_{2} \mathrm{NPs}$, while nanostructure observation exposes that the uniform circulation comprises irregularly shaped morphology. In Fig. 3 (b), it was found that the pristine $\mathrm{a}-\mathrm{Fe}_{2} \mathrm{O}_{3} \mathrm{NPs}$ have composed of the flake-like structures morphology and copious agglomerated certain dispersed NPs [32]. Also, it is observed that $\mathrm{TiO}_{2} / \mathrm{a}-\mathrm{Fe}_{2} \mathrm{O}_{3}$ catalyst composite (Fig. 3 (c)) for the flake-like nanostructured $\mathrm{a}-\mathrm{Fe}_{2} \mathrm{O}_{3}$ materials were self-possessed on $\mathrm{TiO}_{2}$ assembly and fairly agglomerated with randomly distributed, which is supposed to be beneficial for augmenting the catalytic belongings [2]. Besides, EDXS spectrum was used to conclude the elemental weight ratio for the $\mathrm{TiO}_{2} /$ a-Fe $\mathrm{O}_{2} \mathrm{O}_{3}$ composite sample in Fig 3 (d). The outcomes exposed (insert Fig. 3 (d)) that the O, Ti and Fe elements were $42.11 \%, 40.15 \%$ and $17.74 \%$ (weight \%) relatively. The EDXS element mapping images (Fig. 4 (a-d)) of $\mathrm{TiO}_{2} / \mathrm{a}-\mathrm{Fe}_{2} \mathrm{O}_{3}$ composite for auxiliary established that there spatial distribution and the pinpointed/isolated spots of the $\mathrm{O}, \mathrm{Fe}$ and Ti elements [5,33]. Therefore, it is decided that $\mathrm{TiO}_{2} \mathrm{NPs}$ were effectively covered on the even superficial of cubic a- $\mathrm{Fe}_{2} \mathrm{O}_{3} \mathrm{NSs}$.

HRTEM images were demonstrated that $\mathrm{a}-\mathrm{Fe}_{2} \mathrm{O}_{3}$ NPs were uniformly distribution decorated of NPs on the aggregation of $\mathrm{TiO}_{2}$ surfaced spherical morphologies, as obtainable in Fig. 5 (a-f). What's more, the characteristic HR-TEM images have further disclosed that the composite maintains of flake-like structure with homogenous crumpled nanosheets [34]. The lattice fringes of as-achieved heterostructured $\mathrm{TiO}_{2} /$ a- $\mathrm{Fe}_{2} \mathrm{O}_{3}$ composite typically exposed to the (101) facets of $\mathrm{TiO}_{2}$ and (012) crystallographic planes of 
$\mathrm{a}-\mathrm{Fe}_{2} \mathrm{O}_{3}$ are discrete through measured the fringe spacing of $0.31 \mathrm{~nm}$ as presented in Fig. 5 (e, f). Hence the characteristic lattice lines for the selected area electron diffraction (SAED) pattern reveals the highly polycrystalline nature [6] of the NC in Fig. 5 (d). Also confirms the fruitful incorporation of both identical $\mathrm{TiO}_{2}$ into a- $\mathrm{Fe}_{2} \mathrm{O}_{3}$ composite could be probable for the electrostatic interface among negatively charged $\mathrm{TiO}_{2}$ and positively charged $\mathrm{a}-\mathrm{Fe}_{2} \mathrm{O}_{3} \mathrm{NPs}$ which is augmenting the charge carriers separation also notable for enlightened photocatalytic enrichment of $\mathrm{TiO}_{2} / \mathrm{a}-\mathrm{Fe}_{2} \mathrm{O}_{3}$ catalyst [35]. These consequences were which suggest in good promise with that of the XRD outcomes.

To investigate the UV-Vis DRS absorbance spectra of as-fabricated samples were shown in Fig. 6 (A). As revealed in Fig. 6, the UV-Vis absorption edges of pristine $\mathrm{TiO}_{2} \mathrm{NPs}$ are about $\sim 325 \mathrm{~nm}$ in the spectra, whereas endorsed to the electronic transition of $\mathrm{O}_{2 p}$ to $\mathrm{Ti}_{3 d}$ [36]. For pristine $\mathrm{a}-\mathrm{Fe}_{2} \mathrm{O}_{3} \mathrm{NPs}$ exhibit, apparent visible-light absorption is detected in the curve $\left(\lambda_{\mathrm{ab}}\right.$ upto $\left.\sim 590 \mathrm{~nm}\right)$. In contrast, the $\mathrm{TiO}_{2} /$ a- $\mathrm{Fe}_{2} \mathrm{O}_{3}$ composite catalyst presented not only stronger light absorption threshold in the UV region of less than $\sim 390 \mathrm{~nm}$, then the suitable and robust absorption edges found in the visible-light province of 400-700 nm could be witnessed in Fig. 6 (A). These fallouts which proposed that they $\mathrm{TiO}_{2}$ were redshifted into the visible-light after adding the $\mathrm{a}-\mathrm{Fe}_{2} \mathrm{O}_{3}$, hence it has been stated the charge transfer by the direct transition from $02 p$ to $\mathrm{Fe}^{3+}(3 \mathrm{~d})$ could change the visible absorbance to the elongated wavelength from the indirect transition among $\mathrm{Fe}^{3+}(3 d)$ electrons $\left(\mathrm{e}^{-}\right)$[27]. Hence, it has not only encourage the separation and migration of photo-produced charges but also contribute to the $\mathrm{CB}$ in the upper situation. Thus, the UV-Vis spectra effects proved the incorporation of $\mathrm{Fe}^{3+}$ in $\mathrm{TiO}_{2}$. Remarkably, this would be extended the visible-light photocatalytic movement of the heterostructured $\mathrm{TiO}_{2} / \mathrm{a}-\mathrm{Fe}_{2} \mathrm{O}_{3}$ composite photocatalyst, also utilized by realizing the solar light [37].

Figure 6 (B) illustrates the Tauc plots of (ahv) ${ }^{2}$ versus photon energy (hv) for the optical bandgap energies of as-attained catalysts, which were intended founded on the optical absorption edge attained from UV-Vis DRS spectra using Kubelka-Munk Eqn; ahv $=A(h v E g)^{n / 2}$. Wherever, $A, E_{g}, a, h, v$, are the relatively constant, bandgap energy, absorption coefficient, Planck's constant, incident light frequency, and where, $n=1 / 2$, and 2 for direct and indirect bandgap consistently [32]. The outcomes show that the intercepts of band-gap energies of pristine $\mathrm{TiO}_{2}, \mathrm{a}-\mathrm{Fe}_{2} \mathrm{O}_{3}$ and $\mathrm{TiO}_{2} / \mathrm{a}-\mathrm{Fe}_{2} \mathrm{O}_{3} \mathrm{PCs}$ are estimated roughly $3.21,2.11$, and $2.72 \mathrm{eV}$, individually. In the existing form, $\mathrm{Fe}^{3+}$ was mixed with the $\mathrm{TiO}_{2}$ lattice, ensued in the decreasing the bandgap of $\mathrm{TiO}_{2} \mathrm{NPs}$, greatly upgraded to enabled the visible-light fascination assets of the heterostructured $\mathrm{TiO}_{2} / \mathrm{a}-\mathrm{Fe}_{2} \mathrm{O}_{3} \mathrm{PCs}$ [38]. As advised for owed to an exclusive electronic arrangement, implying that the $\mathrm{Fe}^{3+}$ has the ability to the form novel narrowing energy levels occurs in the bandgap of $\mathrm{TiO}_{2} \mathrm{NPs}$ and declines the bandgap with active photo-excitation between VB and CB. This might be correlated to particle size, surface morphology and the novel accumulation of $\mathrm{a}-\mathrm{Fe}_{2} \mathrm{O}_{3}$, as well the Fermi level of $\mathrm{TiO}_{2} / \mathrm{a}-\mathrm{Fe}_{2} \mathrm{O}_{3}$ heterostructured $\mathrm{NC}$ hints to energy bandgap declined [39]. Conferring to the UV-Vis DRS outcomes, the as-fabricated $\mathrm{TiO}_{2} / \mathrm{a}-\mathrm{Fe}_{2} \mathrm{O}_{3} \mathrm{PCs}$ with a narrow bandgap are projected to 
expose the outstanding photocatalytic action for decomposing organic impurities in the visible-light expanse, which agreed to the VLD photo-degrading manner [40].

PL emission spectra could be carried out to explore the efficiency of photo-produced $\left(\mathrm{e}^{-} / \mathrm{h}^{+}\right)$pairs, transfer, separation, trapping, immigration and to understand the rate of charge-carrier recombination in the specified semiconductor PCs, as one of the essential factors disturbing the photocatalytic exploit. Figure 7 ( $\mathrm{A}$ ) confirms the PL spectra of as-obtained heterostructured PCs and the emission intensity peaks of the as-fabricated pristine $\mathrm{TiO}_{2}, \mathrm{a}-\mathrm{Fe}_{2} \mathrm{O}_{3}$ and $\mathrm{TiO}_{2} / \mathrm{a}-\mathrm{Fe}_{2} \mathrm{O}_{3}$ catalyst were at 461,447 and $459 \mathrm{~nm}$, congruently. The $\mathrm{PL}$ emission peak of $\mathrm{TiO}_{2}$ was upper than that of $\mathrm{TiO}_{2} / \mathrm{a}-\mathrm{Fe}_{2} \mathrm{O}_{3} \mathrm{NC}$ which designated that occurrence of $\mathrm{a}-\mathrm{Fe}_{2} \mathrm{O}_{3}$ reduced the $\left(\mathrm{e}^{-} / \mathrm{h}^{+}\right)$recombination rate [41]. In contrast, novel configurations of the heterostructure amongst $\mathrm{a}-\mathrm{Fe}_{2} \mathrm{O}_{3}$ and $\mathrm{TiO}_{2} \mathrm{NMs}$ which declines the PL emission intensity of the near band edge emission (NBE) and might owed to the intrinsic/extrinsic luminescence defects related NBE. The $\mathrm{Fe}^{3+} / \mathrm{Fe}_{2} \mathrm{O}_{3}$ ions could be integrated into the $\mathrm{TiO}_{2}$ lattice either by substituting $\mathrm{Fe}^{3+}$ ions fashioning especially ionized oxygen vacancies $\left(\mathrm{V}_{0}\right)$ or as interstitial of $\mathrm{Fe}^{3+}$. So the lesser $\mathrm{PL}$ emission intensity of the $\mathrm{TiO}_{2} / \mathrm{a}-\mathrm{Fe}_{2} \mathrm{O}_{3} \mathrm{PCs}$ has a significant for the extent of charge separation are specifies the effectively restrained recombination rate primary to admirable light-harvesting capability hence, the photocatalytic efficacy was heightened [28].

\section{Photocatalytic activity analysis}

The photocatalytic efficiency of as-fabricated $\mathrm{TiO}_{2} / \mathrm{a}-\mathrm{Fe}_{2} \mathrm{O}_{3} \mathrm{PCs}$ was widely evaluated by the decomposition of MB dye and the absorption peak declined steadily under visible-light exposure (Fig. 7 (B)) at diverse time intermission from $0 \mathrm{~min}$ to $100 \mathrm{~min}$ [37]. Also, the MB aqueous solution alone without photocatalyst (blank) was directed to check the self-photodegradation of MB dye have exceptionally low and with under dark situation in the existence of PCs hence it has negligible [25]. The photo-degradation efficacy of $\mathrm{C} / \mathrm{C}_{0}$ curves for $\mathrm{MB}$ over as-fabricated $\mathrm{TiO}_{2}$ and $\mathrm{a}-\mathrm{Fe}_{2} \mathrm{O}_{3}$ catalysts were only $33 \%$ and $47.7 \%$, individually. Moreover, the $\mathrm{TiO}_{2} / \mathrm{a}-\mathrm{Fe}_{2} \mathrm{O}_{3}$ heterostructured composite catalyst resulting in the superior photocatalytic activity (92.7\%) could be achieved amongst all the as-fabricated PCs after 100 mins of visible-light exposure. Figure $8(A)$ demonstrates the consistent concentration changes of the MB aqueous dye solution and the response rate $(k)$ as a function of visible-light exposure time [35]. The photo-degradation proficiencies of $\mathrm{MB}$ aqueous dye by as-obtained PCs are originated to the succeeding order: $\mathrm{TiO}_{2} / \mathrm{a}-\mathrm{Fe}_{2} \mathrm{O}_{3}>\mathrm{a}-\mathrm{Fe}_{2} \mathrm{O}_{3}>\mathrm{TiO}_{2}$.

In order to quantitatively discover the kinetics of MB dye photodegradation under visible-light exposure for the as-fabricated PCs were investigated as shown in Fig. 8 (B), and this suggests that pseudo-firstorder kinetics reaction rates. The specious reaction rate constants $(\mathrm{k})$ for as-fabricated $\mathrm{TiO}_{2}, \mathrm{a}-\mathrm{Fe}_{2} \mathrm{O}_{3}$ and $\mathrm{TiO}_{2} / \mathrm{a}-\mathrm{Fe}_{2} \mathrm{O}_{3} \mathrm{PCs}$ were determined as $0.0071 \mathrm{~min}^{-1}, 0.0109 \mathrm{~min}^{-1}$, and $0.0252 \mathrm{~min}^{-1}$ relatively. It was found that the maximum photocatalytic performance for the decomposition of $\mathrm{MB}$ aqueous dye, which was about 3.54 and 2.31 times greater that of as-fabricated $\mathrm{TiO}_{2}$ and $\mathrm{a}-\mathrm{Fe}_{2} \mathrm{O}_{3}$ catalyst under the identical 
conditions respectively [42]. Besides to photocatalytic efficacy, the stability of the specified photocatalyst is also essential for practical use for the handling of organic impurities in wastewater [30]. To inspect the reusability and stability of $\mathrm{TiO}_{2} / \mathrm{a}-\mathrm{Fe}_{2} \mathrm{O}_{3}$, the $\mathrm{PCs}$ after photocatalysis progression were composed and reused for five successive times under the identical settings. As publicized in Fig. 9 (A), the $\mathrm{TiO}_{2} / \mathrm{a}-\mathrm{Fe}_{2} \mathrm{O}_{3}$ PCs revealed noble reusability throughout five photo-decomposition reuses [37]. After five recycles of photo-reduction of $\mathrm{MB}$ dye, the $\mathrm{TiO}_{2} / \mathrm{a}-\mathrm{Fe}_{2} \mathrm{O}_{3} \mathrm{PCs}$ did not display any significant loss of activity Fig. $8(\mathrm{~A})$, hence it's understood the stability of catalyst after four consecutive catalytic reprocess. Since there was a substantial drop in the fifth recycle $(80.6 \%)$, which was ascribed to the loss of a- $\mathrm{Fe}_{2} \mathrm{O}_{3}$ catalyst during the recycling reaction. The crystalline structure and their functional groups were characterized by XRD and FT-IR individually. Hence the $\mathrm{TiO}_{2} / \mathrm{a}-\mathrm{Fe}_{2} \mathrm{O}_{3} \mathrm{PCs}$ have almost no obvious structural changes were found in before and after the photocatalytic recycles investigates (Fig. 10 (A) and (B)) which outcomes signifying a good stable adequate for recycling [43]. Therefore, $\mathrm{TiO}_{2} / \mathrm{a}-\mathrm{Fe}_{2} \mathrm{O}_{3}$ heterostructured $\mathrm{PCs}$ are projected to be promising in environmental remediation since not only tremendous photocatalytic stability, also enabled energy conversion in the visible-light region [44, 45]. In contrast, with the earlier reported literature of various NCs for photodegradation of organic impurities, $\mathrm{TiO}_{2} / \mathrm{a}-\mathrm{Fe}_{2} \mathrm{O}_{3}$ composite PCs have displayed superb removal efficacy for MB dye, as tabularized in Table 1.

To validate the radicals of NCs in the photocatalytic decomposition process, the trapping investigates of reactive species are executed. Figure 9 (B) displays the three diverse quenching manners, for instance, 0.5 $\mathrm{mM}$ of isopropanol (IPA), disodium ethylene diamine-tetra acetate (EDTA-2Na), and benzoquinone (BQ) were used to sense the scavengers of hydroxyl radicals $\left(\%{ }^{\circ} \mathrm{OH}^{-}\right)$, holes $\left(\% \mathrm{~h}^{+}\right)$and superoxide anion radicals $\left(\% \mathrm{O}_{2}{ }^{-}\right)$absolutely [41]. As could be realized in Fig. 8 (B) the decomposition rate of PCs slightly decreases corresponding to the adding of $\mathrm{BQ}$ and EDTA-2 $\mathrm{Na}$, signifying that which $\% \mathrm{~h}^{+}$and $\%{ }^{\circ} \mathrm{O}_{2}{ }^{-}$are the slight responsive species on this concerned structures. Nevertheless, the accumulation of IPA caused apparent deactivation of the photocatalyst, decreasing the photocatalytic movement for the decomposition rated from $92.7 \%$ to $16 \%$ as exposed in the quenching investigation outcomes. This noticeably validates that active ${ }^{\circ} \mathrm{OH}^{-}$radicals are the foremost reactive species liable for VLD photocatalytic decolourization scheme over these $\mathrm{TiO}_{2} / \mathrm{a}-\mathrm{Fe}_{2} \mathrm{O}_{3}$ heterostructured PCs [46]. 
Table 1

Comparison of VLD photocatalytic degradation of MB dye (\%) over of previous literature reported catalytic NMs

\begin{tabular}{|llllll|}
\hline $\begin{array}{l}\text { S. } \\
\text { No. }\end{array}$ & Photocatalysts & Dye & $\begin{array}{l}\text { Irradiation time } \\
\text { (min.) }\end{array}$ & $\begin{array}{l}\text { Degradation efficiency } \\
\text { (\%) }\end{array}$ & Ref. \\
\hline 1. & $\mathrm{Ga}-\mathrm{Ag} / \mathrm{ZnO}$ & $\mathrm{MB}$ & 300 & $\sim 39$ & {$[44]$} \\
\hline 2. & $\mathrm{P} 25 \mathrm{TiO}_{2}$ & $\mathrm{MB}$ & 300 & $\sim 48$ & {$[47]$} \\
\hline 3. & $\mathrm{CNTs} / \mathrm{TiO}_{2} / \mathrm{Ag}$ & $\mathrm{MB}$ & 240 & $\sim 48$ & {$[48]$} \\
\hline 4. & $\mathrm{ZnO}_{\mathrm{SnO}_{2}}$ & $\mathrm{MB}$ & 240 & $\sim 90$ & {$[49]$} \\
\hline 5. & $\mathrm{TiO}_{2} / \mathrm{CeO}_{5}$ & $\mathrm{MB}$ & 150 & $\sim 95$ & {$[30]$} \\
\hline 6. & $\mathrm{CdS} / \mathrm{TiO}_{2}$ & $\mathrm{MB}$ & 180 & $\sim 63$ & {$[25]$} \\
\hline 7. & $\mathrm{Fe}_{2} \mathrm{O}_{3} / \mathrm{Cu}_{2} \mathrm{O}$ & $\mathrm{MB}$ & 80 & $\sim 40$ & {$[50]$} \\
\hline 8. & $\begin{array}{l}\mathrm{TiO} \\
2\end{array} \mathrm{a}-\mathrm{Fe}_{2} \mathrm{O}_{3}$ & $\mathrm{MB}$ & 100 & $\sim 92.7$ & This work \\
\hline
\end{tabular}

On the base of the upstairs debate, it is noticeable that the generation and $\left(\mathrm{e}^{-}-\mathrm{h}^{+}\right)$separation process mechanism could be proficiently indorsed by the interface between $\mathrm{TiO}_{2}$ and $\mathrm{a}-\mathrm{Fe}_{2} \mathrm{O}_{3}$ catalyst under visible-light exposure [28]. The VB and $\mathrm{CB}$ edge potential position could be gathered via according to the Mulliken electronegativity theory for following Eqn; $E_{V B}=\chi-E_{e}+0.5 E_{g}$ and $E_{C B}=E_{V B}-E_{g}$. Wherein, $\chi$ signifies the absolute Mulliken electronegativity of given $\mathrm{SCs}\left(\chi \mathrm{TiO}_{2}=5.81 \mathrm{eV}\right.$, and $\left.\chi \mathrm{a}-\mathrm{Fe}_{2} \mathrm{O}_{3}=5.88 \mathrm{eV}\right)$, separately [51]. Moreover, the $\mathrm{E}_{\mathrm{g}}, \mathrm{E}_{\mathrm{e}}, \mathrm{E}_{\mathrm{VB}}$ and $\mathrm{E}_{\mathrm{CB}}$ were energy bandgap of specified SCs by UV-DRS spectra $\left(\mathrm{E}_{\mathrm{g}}\right.$ of $\mathrm{TiO}_{2}=3.21 \mathrm{eV} ; \mathrm{E}_{\mathrm{g}}$ of $\left.\mathrm{a}-\mathrm{Fe}_{2} \mathrm{O}_{3}=2.11 \mathrm{eV}\right)$, the energy of free electrons on the hydrogen scale (ca. $4.5 \mathrm{eV}$ ), VB edge potential and CB edge potential individually [52]. Agreeing to the above equations, the energy level diagram is based upon the $\mathrm{E}_{\mathrm{VB}}$ and $\mathrm{E}_{\mathrm{CB}}$ values were estimated to be of $\operatorname{TiO}_{2}\left(\mathrm{E}_{\mathrm{VB}}=2.915\right.$, $\left.\mathrm{E}_{\mathrm{CB}}=-0.295\right)$ and its favorable than $\mathrm{a}-\mathrm{Fe}_{2} \mathrm{O}_{3}\left(\mathrm{E}_{\mathrm{VB}}=2.48, \mathrm{E}_{\mathrm{CB}}=0.28\right)$ discretely.

Based on the upstairs analysis and conversation, the photo-produced charge separation and transfer of the $\mathrm{TiO}_{2} / \mathrm{a}-\mathrm{Fe}_{2} \mathrm{O}_{3}$ heterostructured catalyst for the improved plausible photocatalytic action in visible-light preservation could be anticipated as exposed above trial outcomes in Fig. 11. Under the visible-light illumination $(\lambda>420 \mathrm{~nm})$, both the $\mathrm{SCs}$ catalysts of $\mathrm{TiO}_{2}$ and a-Fe $\mathrm{Fe}_{2} \mathrm{O}_{3}$ catalyst are photo-excited primarily by photons while to produce more electron-hole $\left(\mathrm{e}^{-}-\mathrm{h}^{+}\right)$pairs, which are then separated and stimulated to diverse ways under the reaction energy [32]. In detail, the photo-electrons $\left(\mathrm{e}^{-}\right)$of $\mathrm{TiO}_{2}$ will transfer to the $\mathrm{CB}$ of $\mathrm{a}-\mathrm{Fe}_{2} \mathrm{O}_{3}$, meanwhile, the photo-holes $\left(\mathrm{h}^{+}\right)$of $\mathrm{a}-\mathrm{Fe}_{2} \mathrm{O}_{3}$ will transport to the $\mathrm{VB}$ of $\mathrm{TiO}_{2}(\mathrm{Ti} 3 \mathrm{~d})$ under the exploit of a built-in electric field. Though, under the energetic reaction in the photo-electrons $\left(\mathrm{e}^{-}\right)$of $\mathrm{a}-\mathrm{Fe}_{2} \mathrm{O}_{3}$ and the photo-holes $\left(\mathrm{h}^{+}\right)$of $\mathrm{TiO}_{2}$ would exchange to both other and then concluding the 
consequence of $\left(\mathrm{e}^{-}-\mathrm{h}^{+}\right)$recombination. In photocatalytic system, the photo-electrons $\left(\mathrm{e}^{-}\right)$prompt to the reduction of $\mathrm{Fe}^{3+}$ ions to $\mathrm{Fe}^{2+}$ ions [50]. When a- $\mathrm{Fe}_{2} \mathrm{O}_{3} \mathrm{NPs}$ were united with $\mathrm{TiO}_{2} \mathrm{NPs}$, the Fermi level of $\mathrm{TiO}_{2}$ and a- $\mathrm{Fe}_{2} \mathrm{O}_{3}$ necessity align in symmetry owed to the occurrence of the $\mathrm{TiO}_{2} / \mathrm{a}-\mathrm{Fe}_{2} \mathrm{O}_{3}$ heterojunction [27]. The authority of $\mathrm{TiO}_{2} / \mathrm{a}-\mathrm{Fe}_{2} \mathrm{O}_{3} \mathrm{NSs}$ also profits from the pairing by narrow bandgap semiconductor $a-\mathrm{Fe}_{2} \mathrm{O}_{3}$. Thus the $\left(\mathrm{e}^{-} / \mathrm{h}^{+}\right)$recombination progression is greatly suppressed and efficient $\left(\mathrm{e}^{-} / \mathrm{h}^{+}\right)$ separation is realized on the $\mathrm{NC}$ surface [47]. In this case, the presence of $\mathrm{TiO}_{2} / \mathrm{a}-\mathrm{Fe}_{2} \mathrm{O}_{3}$ fitted heterostructures, the conversion of the photo-electrons $\left(\mathrm{e}^{-}\right)$and the photo-holes $\left(\mathrm{h}^{+}\right)$would primary go through the hybrid layer simply owed the firm migration rate position which also stimulates the outstanding charge separation movement. Concurrently, the samples of $\mathrm{TiO}_{2}$ and a- $\mathrm{Fe}_{2} \mathrm{O}_{3} \mathrm{PCs}$ will efforts to the photo-oxidation and reduction situates also the virtual interesting water oxidation for the photodegradation reaction could be attained, exclusively [1]. Also, the photo-electrons ( $\left.e^{-}\right)$in the VB of $\mathrm{TiO}_{2}$ was auxiliary respond with molecular oxygen $\mathrm{O}_{2}$ dissolved in the solution to form the superoxide anion $\left(\mathrm{O}_{2}{ }^{\cdot-}\right)$ and hydrogen peroxide $\left(\mathrm{H}_{2} \mathrm{O}_{2}\right)$. Consecutively, the photodegradation of $\mathrm{MB}$ dye is reached by capture the photo-electrons $\left(\mathrm{e}^{-}\right)$and the photo-holes $\left(\mathrm{h}^{+}\right)$could also oxidize either the organic molecule directly and/or the $\mathrm{OH}$ ions $\mathrm{H}_{2} \mathrm{O}$ fragments are adsorbed on the catalytic surface to the sturdy oxidizing to reactive ${ }^{\prime} \mathrm{OH}^{-}$radicals by the end products on the photocatalyst surface [42]. Our consequences exposed that the construction of $\mathrm{TiO}_{2} / \mathrm{a}-\mathrm{Fe}_{2} \mathrm{O}_{3} \mathrm{PCs}$ hinder the recombination of photo-excited electron-hole $\left(\mathrm{e}^{-}-\mathrm{h}^{+}\right)$ pairs and encourage the generation of $\mathrm{more}^{\circ} \mathrm{OH}^{-}$radicals resulted in the development of photodegradation competence of $\mathrm{TiO}_{2} / \mathrm{a}-\mathrm{Fe}_{2} \mathrm{O}_{3} \mathrm{PCs}$ [25]. While the amassed photo-holes $\left(\mathrm{h}^{+}\right)$in the $\mathrm{VB}$ of $\mathrm{Fe}_{2} \mathrm{O}_{3}$ respond with $\mathrm{OH}^{-}$species or $\mathrm{H}_{2} \mathrm{O}^{\circ}$ prevailing on the surface of the $\mathrm{PCs}$, fabricating responsive hydroxyl radicals $\left({ }^{\circ} \mathrm{OH}^{-}\right)$which are auxiliary intricate in the photodegradation of $\mathrm{MB}$ dye, as presented in Fig. 11. To conclude, the organic-acids were photo-oxidized to form into the harmless ingredients of $\mathrm{CO}_{2}$ and $\mathrm{H}_{2} \mathrm{O}[53,54]$. This reaction could be responsible for specified by equations (1)-(5);

$$
\begin{gathered}
\mathrm{TiO}_{2} / \alpha \mathrm{Fe}_{2} \mathrm{O}_{3}+\text { Dye }+ \text { h } v \text { Light } \rightarrow \mathrm{TiO}_{2} / \alpha \mathrm{Fe}_{2} \mathrm{O}_{3}+\text { Dye }+\left(e^{-}(C B)+h^{+}(V B)\right) \rightarrow(1) \\
\text { Dye }+e^{-}(\mathrm{CB}) \rightarrow \text { Reduction products } \rightarrow(2) \\
\text { Dye }+\mathrm{O}_{2} \rightarrow \mathrm{O}_{2}^{-}+\text {Degradation products } \rightarrow(3) \\
\text { Dye }+h^{+}(\mathrm{VB}) \rightarrow \text { Oxidative products } \rightarrow(4)
\end{gathered}
$$$$
\text { Dye }+\mathrm{OH} \rightarrow \mathrm{OH}^{--}+\mathrm{H}_{2} \mathrm{O}+\text { Degradation products } \rightarrow(5)
$$

\section{Conclusion}

In summary, $\mathrm{TiO}_{2} / \mathrm{a}-\mathrm{Fe}_{2} \mathrm{O}_{3}$ composite catalysts were efficiently fabricated by hydrothermal assisted precipitation manner and enhanced VLD photocatalytic actions were also surveyed. The powder XRD diffraction pattern peaks of $\mathrm{TiO}_{2}$ and $\mathrm{a}-\mathrm{Fe}_{2} \mathrm{O}_{3} \mathrm{NPs}$ were well accorded with the tetragonal (anatase) and rhombohedral phases are obtained. The narrow bandgap of $\mathrm{a}-\mathrm{Fe}_{2} \mathrm{O}_{3}$ was engaged to outspread the 
optical response of $\mathrm{TiO}_{2}$ to the visible-light region. Though $\mathrm{TiO}_{2} / \mathrm{a}-\mathrm{Fe}_{2} \mathrm{O}_{3}$ sample has revealed the premier photocatalytic action of the organic $\mathrm{MB}$ aqueous dye among other as-fabricated $\mathrm{TiO}_{2}$ and a- $\mathrm{Fe}_{2} \mathrm{O}_{3} \mathrm{PCs}$ in the visible-light region. The photocatalytic materials also exhibit adequate superior cyclic stability and the dye decomposition efficiency could be $80.6 \%$ after five successive cycle runs. It is accredited to the wellsuited interface fashioned heterojunction structures between $\mathrm{TiO}_{2}$ and $\mathrm{a}-\mathrm{Fe}_{2} \mathrm{O}_{3}$, which promotes the efficient photo-produced $\left(\mathrm{e}^{-}-\mathrm{h}^{+}\right)$charge transfer/separation, restraining the recombination rate, with prolonged optical absorption into the visible region and favourable ${ }^{\circ} \mathrm{OH}^{-}$radicals invention ability. To conclude, a promising photocatalytic mechanism is projected for this novel PCs. Here consider that the expansion of the great photocatalytic actions of $\mathrm{TiO}_{2} / \mathrm{a}-\mathrm{Fe}_{2} \mathrm{O}_{3}$ heterostructures will deliver an auspicious platform for the highly stable and reusable performance of photocatalytic practical applications.

\section{Declarations}

The authors have declares no conflict of interest.

\section{References}

1. G.K. Upadhyay, J.K. Rajput, T.K. Pathak, V. Kumar, L.P. Purohit, Vacuum 160, 154 (2019)

2. Y. Koo, G. Littlejohn, B. Collins, Y. Yun, V.N. Shanov, M. Schulz, D. Pai, J. Sankar, Composites Part B: Engineering 57, 105 (2014)

3. S. He, P. Hou, E. Petropoulos, Y. Feng, Y. Yu, L. Xue, L. Yang, Front. Chem. 6, 1 (2018)

4. M. Wang, Y. Hu, J. Han, R. Guo, H. Xiong, Y. Yin, Journal of Materials Chemistry A 3, 20727 (2015)

5. L. Kong, J. Yan, P. Li, S.F. Liu, ACS Sustainable Chemistry and Engineering 6, 10436 (2018)

6. G.R. Surikanti, A.K. Bandarapu, M.V. Sunkara, ChemistrySelect 4, 2249 (2019)

7. P. Pooseekheaw, W. Thongpan, A. Panthawan, E. Kantarak, W. Sroila, P. Singjai, Molecules 25, 3327 (2020)

8. W.K. Jo, T. Adinaveen, J.J. Vijaya, N.C. Sagaya, Selvam, RSC Advances 6, 10487 (2016)

9. A. Leelavathi, B. Mukherjee, C. Nethravathi, S. Kundu, M. Dhivya, N. Ravishankar, G. Madras, RSC Advances 3, 20970 (2013)

10. J. Sun, X. Li, Q. Zhao, J. Ke, D. Zhang, J. Phys. Chem. C 118, 10113 (2014)

11. M.S.S. Danish, A. Bhattacharya, D. Stepanova, A. Mikhaylov, M.L. Grilli, M. Khosravy, T. Senjyu, Metals 10, 1604 (2020)

12. W. K. Jo and N. Clament Sagaya Selvam, Journal of Hazardous Materials 299, 462 (2015)

13. S. Martha, P. Chandra Sahoo, K.M. Parida, RSC Advances 5, 61535 (2015)

14. C. Karthikeyan, P. Arunachalam, K. Ramachandran, A.M. Al-Mayouf, S. Karuppuchamy, J. Alloy. Compd. 828, 154281 (2020)

15. S. Gautam, H. Agrawal, M. Thakur, A. Akbari, H. Sharda, R. Kaur, M. Amini, Journal of Environmental Chemical Engineering 8, 103726 (2020) 
16. A. Gołąbiewska, M.P. Kobylański, A. Zaleska-Medynska, in Metal Oxide-Based Photocatalysis: Fundamentals and Prospects for Application (Elsevier, 2018), pp. 3-50

17. M.M. Mohamed, W.A. Bayoumy, M.E. Goher, M.H. Abdo, and T. Y. Mansour El-Ashkar, Applied Surface Science 412, 668 (2017)

18. W.K. Jo, N.C.S. Selvam, Dalton Trans. 44, 16024 (2015)

19. L. Xu, J. Wang, Environ. Sci. Technol. 46, 10145 (2012)

20. S. Balu, S. Velmurugan, S. Palanisamy, S.W. Chen, V. Velusamy, T.C.K. Yang, and E. S. I. El-Shafey. J. Taiwan Inst. Chem. Eng. 99, 258 (2019)

21. L. Baia, E. Orbán, S. Fodor, B. Hampel, E.Z. Kedves, K. Saszet, I. Székely, É Karácsonyi, B. Réti, P. Berki, A. Vulpoi, K. Magyari, A. Csavdári, C. Bolla, V. Coşoveanu, K. Hernádi, M. Baia, A. Dombi, V. Danciu, G. Kovács, Z. Pap, Mater. Sci. Semicond. Process. 42, 66 (2016)

22. A.M. Abdel-Wahab, A.S. Al-Shirbini, O. Mohamed, O. Nasr, J. Photochem. Photobiol., A 347, 186 (2017)

23. S. Ma, S. Zhan, Y. Jia, Q. Zhou, ACS Applied Materials and Interfaces 7, 10576 (2015)

24. D. He, Y. Yang, J. Tang, K. Zhou, W. Chen, Y. Chen, Z. Dong, Environ. Sci. Pollut. Res. 26, 12359 (2019)

25. H. Wei, L. Wang, Z. Li, S. Ni, Q. Zhao, Nano-Micro Letters 3, 6 (2011)

26. K. Kaviyarasan, V. Vinoth, T. Sivasankar, A.M. Asiri, J.J. Wu, S. Anandan, Ultrason. Sonochem. 51, 223 (2019)

27. X. Lu, X. Li, F. Chen, Z. Chen, J. Qian, Q. Zhang, J. Alloy. Compd. 815, 152326 (2020)

28. J. Tian, P. Hao, N. Wei, H. Cui, H. Liu, ACS Catalysis 5, 4530 (2015)

29. B. Singaram, K. Varadharajan, J. Jeyaram, R. Rajendran, V. Jayavel, J. Photochem. Photobiol., A 349, 91 (2017)

30. J.C. Cano-Franco, M. Álvarez-Láinez, Mater. Sci. Semicond. Process. 90, 190 (2019)

31. M. Fakhrul Ridhwan Samsudin, S. Sufian, R. Bashiri, N. Muti Mohamed, L. Tau, Siang, R. Mahirah, Ramli, Materials Today: Proceedings 5, 21710 (2018)

32. W.A. Aboutaleb, R.A. El-Salamony, Mater. Chem. Phys. 236, 121724 (2019)

33. L. Zhu, H. Li, Z. Liu, P. Xia, Y. Xie, D. Xiong, J. Phys. Chem. C 122, 9531 (2018)

34. S. Chandrasekaran, W.M. Choi, J.S. Chung, S.H. Hur, E.J. Kim, Mater. Lett. 136, 118 (2014)

35. V. Ramasamy Raja, A. Karthika, S. Lok Kirubahar, A. Suganthi, M. Rajarajan, Solid State Ionics 332, $55(2019)$

36. D. Lu, B. Zhao, P. Fang, S. Zhai, D. Li, Z. Chen, W. Wu, W. Chai, Y. Wu, N. Qi, Appl. Surf. Sci. 359, 435 (2015)

37. N.S. Arul, D. Mangalaraj, R. Ramachandran, A.N. Grace, J.I. Han, Journal of Materials Chemistry A 3, 15248 (2015)

38. B. Sharma, P.K. Boruah, A. Yadav, M.R. Das, Journal of Environmental Chemical Engineering 6, 134 (2018) 
39. J. Qin, C. Yang, M. Cao, X. Zhang, R. Saravanan, S. Limpanart, M. Ma, R. Liu, Mater. Lett. 189, 156 (2017)

40. G.K. Upadhyay, J.K. Rajput, T.K. Pathak, V. Kumar, L.P. Purohit, Vacuum 160, 154 (2019)

41. L. Rožić, S. Petrović, D. Lončarević, B. Grbić, N. Radić, S. Stojadinović, V. Jović, J. Lamovec, Ceram. Int. 45, 2361 (2019)

42. L. Zhu, H. Li, Z. Liu, P. Xia, Y. Xie, D. Xiong, J. Phys. Chem. C 122, 9531 (2018)

43. A.B. Ali Baig, V. Rathinam, J. Palaninathan, Applied Water Science 10, 54 (2020)

44. M.N. Cardoza-Contreras, A. Vásquez-Gallegos, A. Vidal-Limon, J.M. Romo-Herrera, S. Águila, O.E. Contreras, Catalysts 9, 1 (2019)

45. Y. Lei, J. Huo, H. Liao, RSC Advances 7, 40621 (2017)

46. A.B. Ali Baig, V. Rathinam, V. Ramya, Materials Technology 1 (2020)

47. M. Gurulakshmi, M. Selvaraj, A. Selvamani, P. Vijayan, N.R. Sasi, Rekha, K. Shanthi, Appl. Catal. A 449, 31 (2012)

48. Y. Koo, G. Littlejohn, B. Collins, Y. Yun, V.N. Shanov, M. Schulz, D. Pai, J. Sankar, Composites Part B: Engineering 57, 105 (2014)

49. M.M. Rashad, A.A. Ismail, I. Osama, I.A. Ibrahim, A.-H.T. Kandil, Arabian Journal of Chemistry 7, 71 (2014)

50. S.K. Lakhera, R. Venkataramana, A. Watts, M. Anpo, B. Neppolian, Res. Chem. Intermed. 43, 5091 (2017)

51. R. Saravanan, V.K. Gupta, E. Mosquera, F. Gracia, J. Mol. Liq. 198, 409 (2014)

52. D. Zhang, S. Cui, J. Yang, J. Alloy. Compd. 708, 1141 (2017)

53. R. Li, Y. Jia, N. Bu, J. Wu, Q. Zhen, J. Alloy. Compd. 643, 88 (2015)

54. Z. Zhang, Y. Ma, X. Bu, Q. Wu, Z. Hang, Z. Dong, X. Wu, Sci. Rep. 8, 10532 (2018)

\section{Figures}



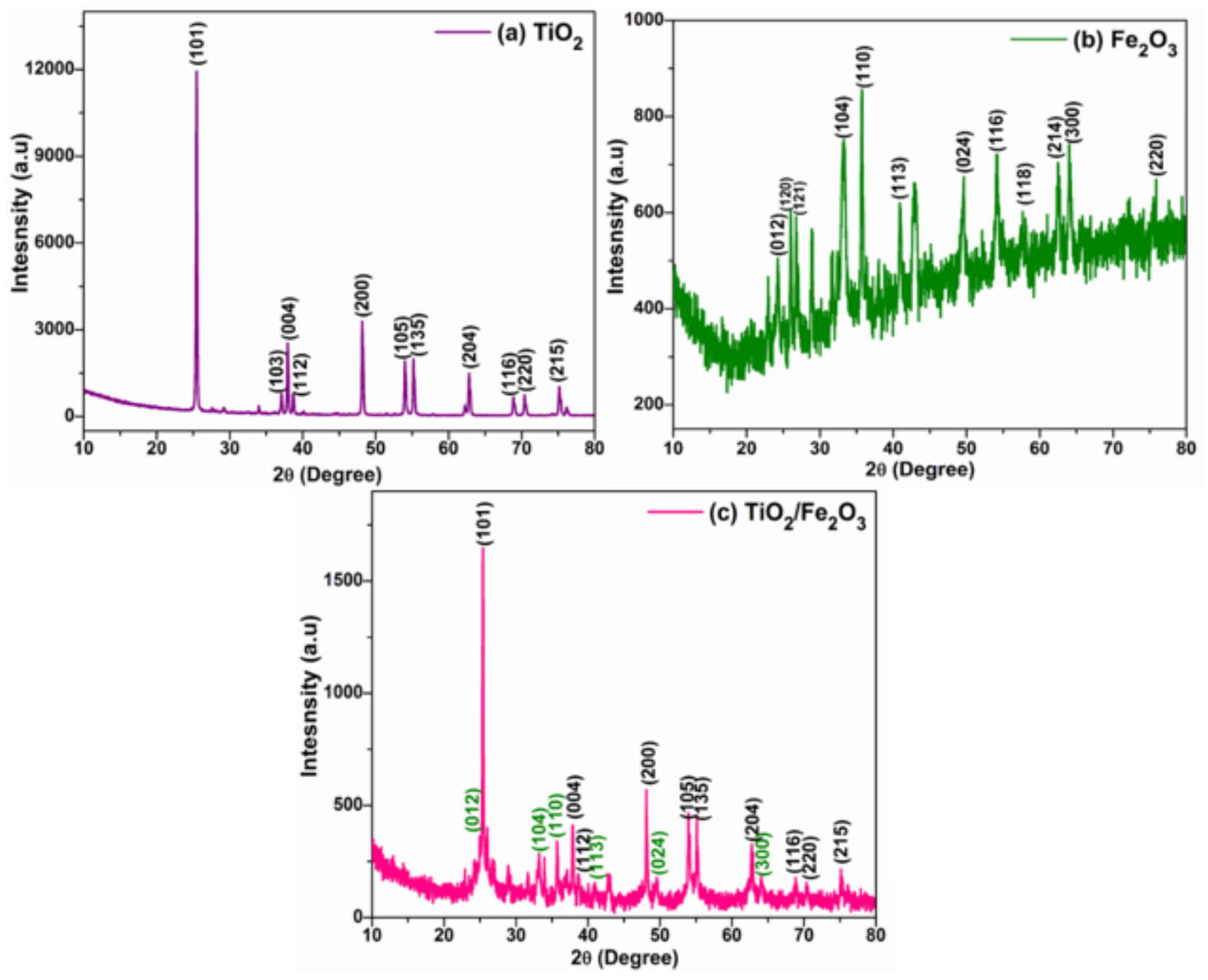

Figure 1

Powder XRD pattern of as-obtained samples 


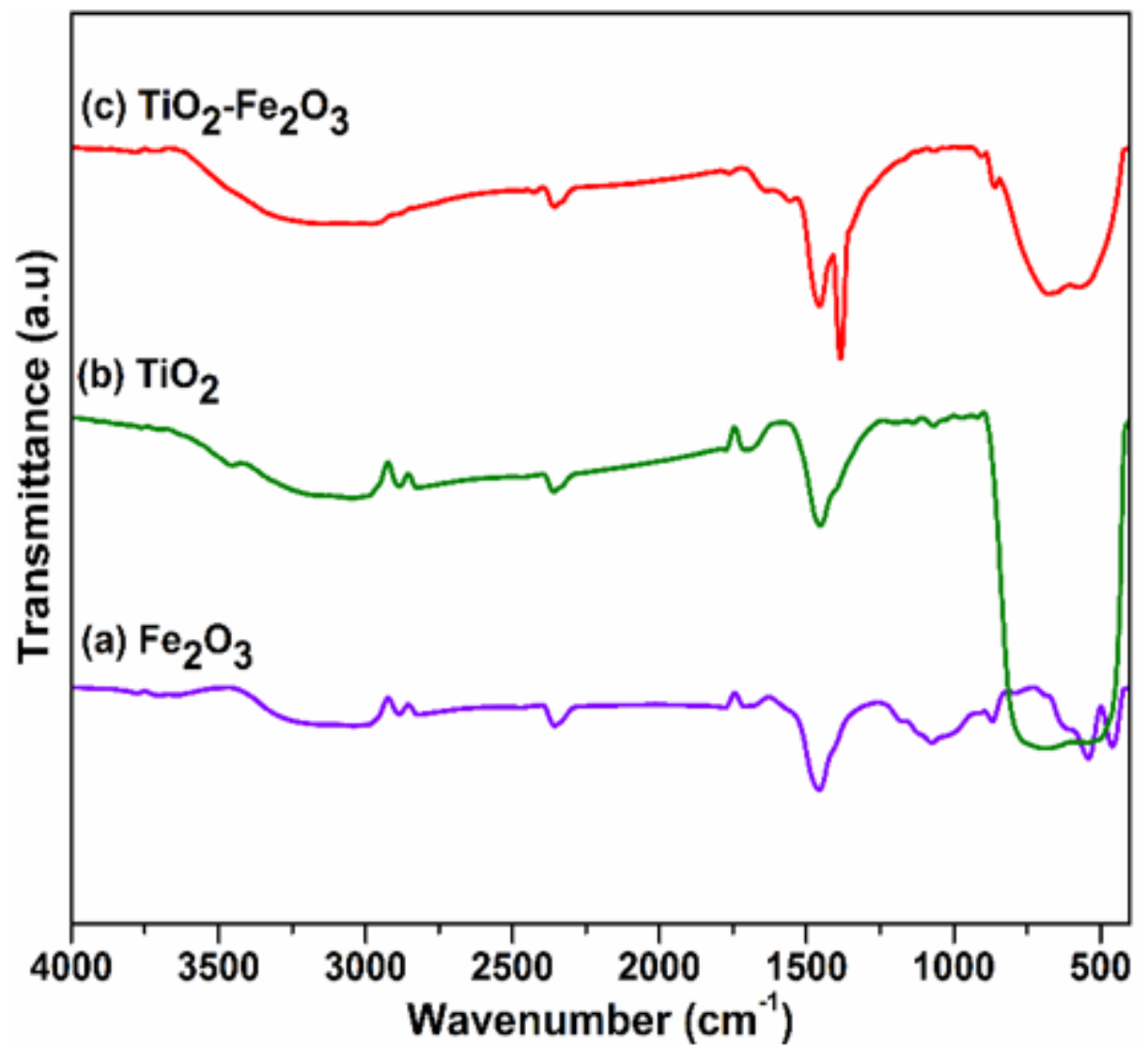

Figure 2

FT-IR spectra of as-obtained samples 

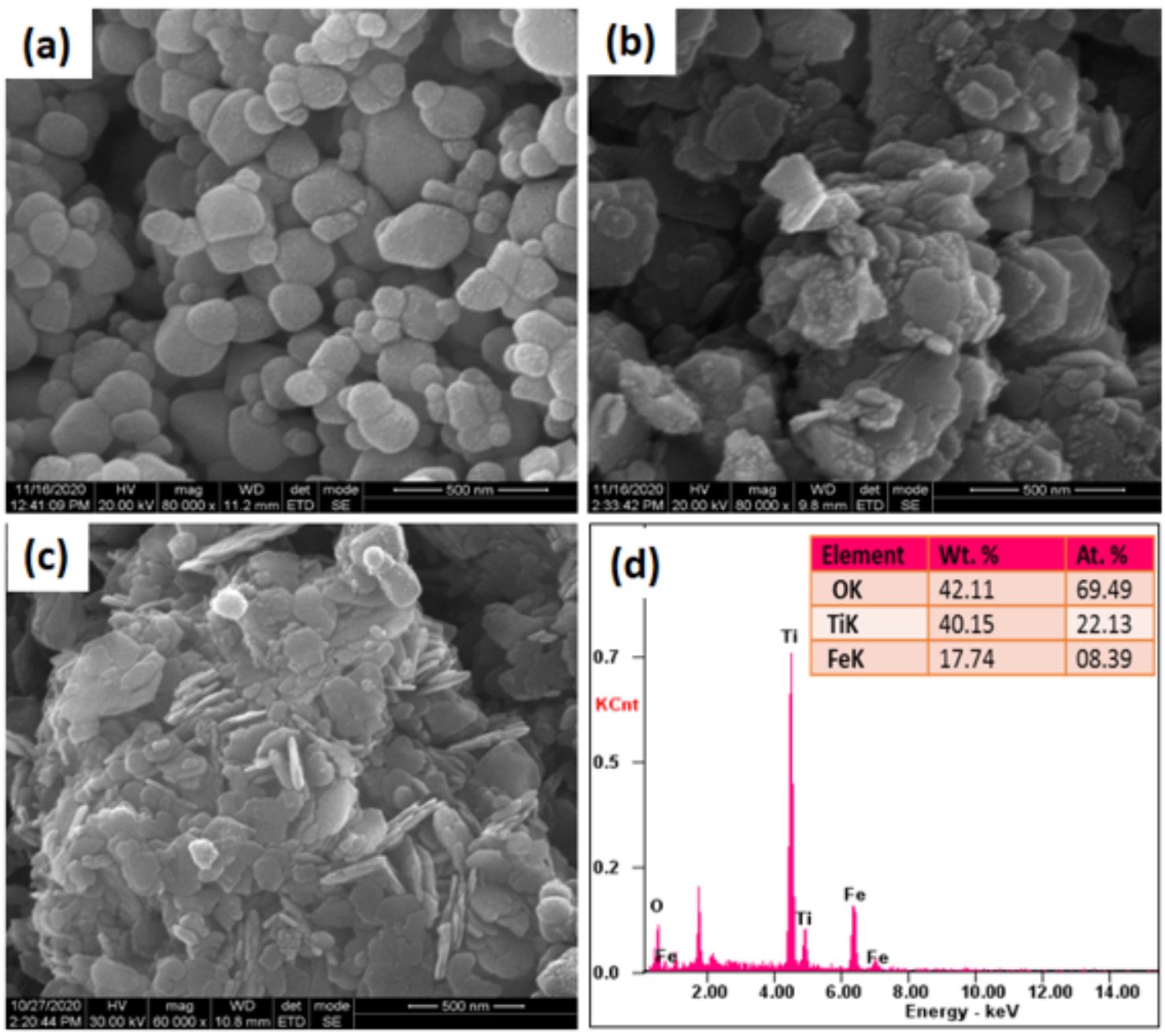

Figure 3

HRSEM images of as-fabricated (a) pristine TiO2 (b) a-Fe2O3 (c) TiO2/a-Fe2O3 composite and (d) consistent EDXS spectrum of TiO2/a-Fe2O3 composite 

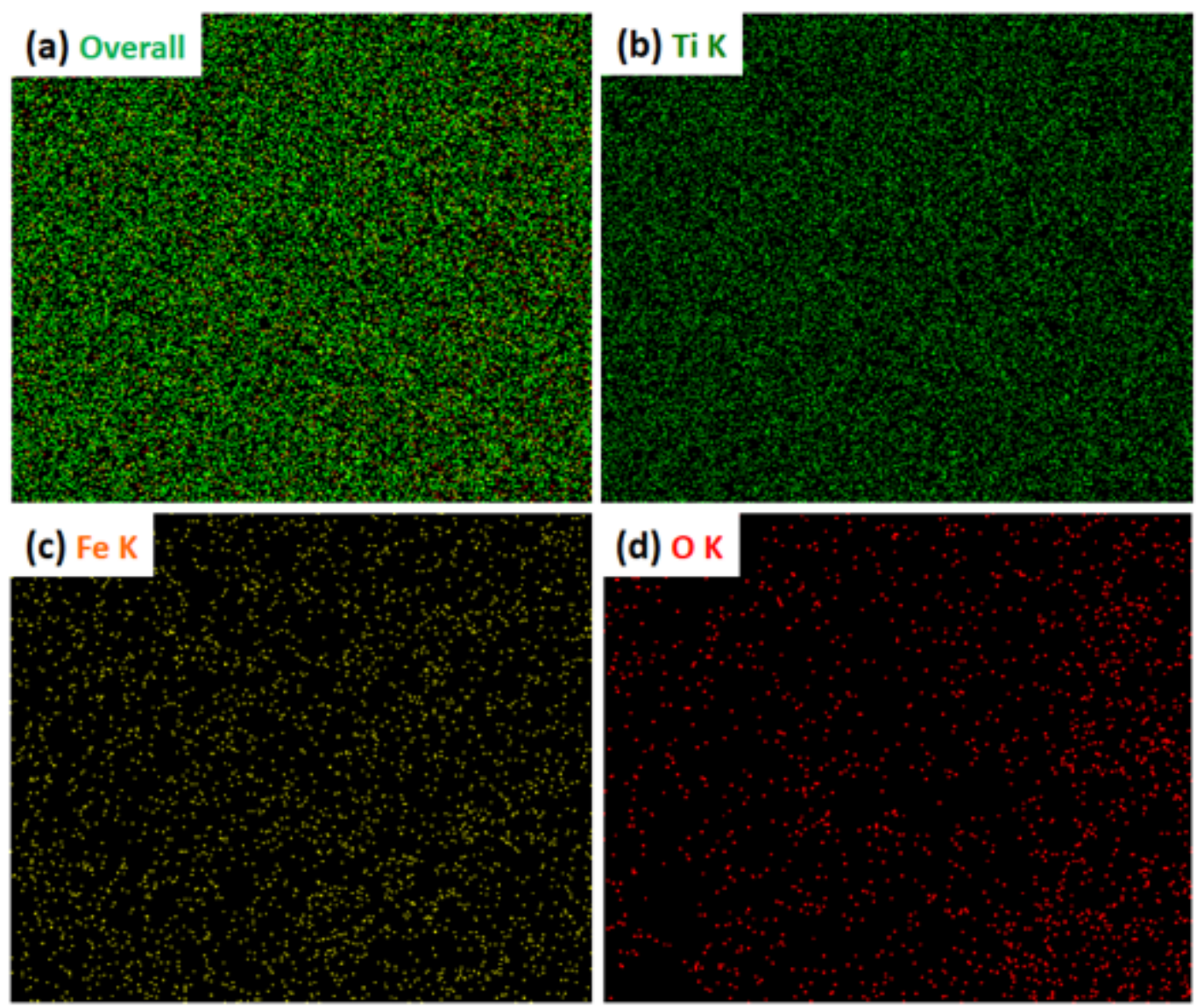

(d) $\mathrm{OK}$

Figure 4

EDXS elemental mapping of TiO2/a-Fe2O3 NC; Pictures of (b) Ti, (c) Fe and (d) 0 elements 

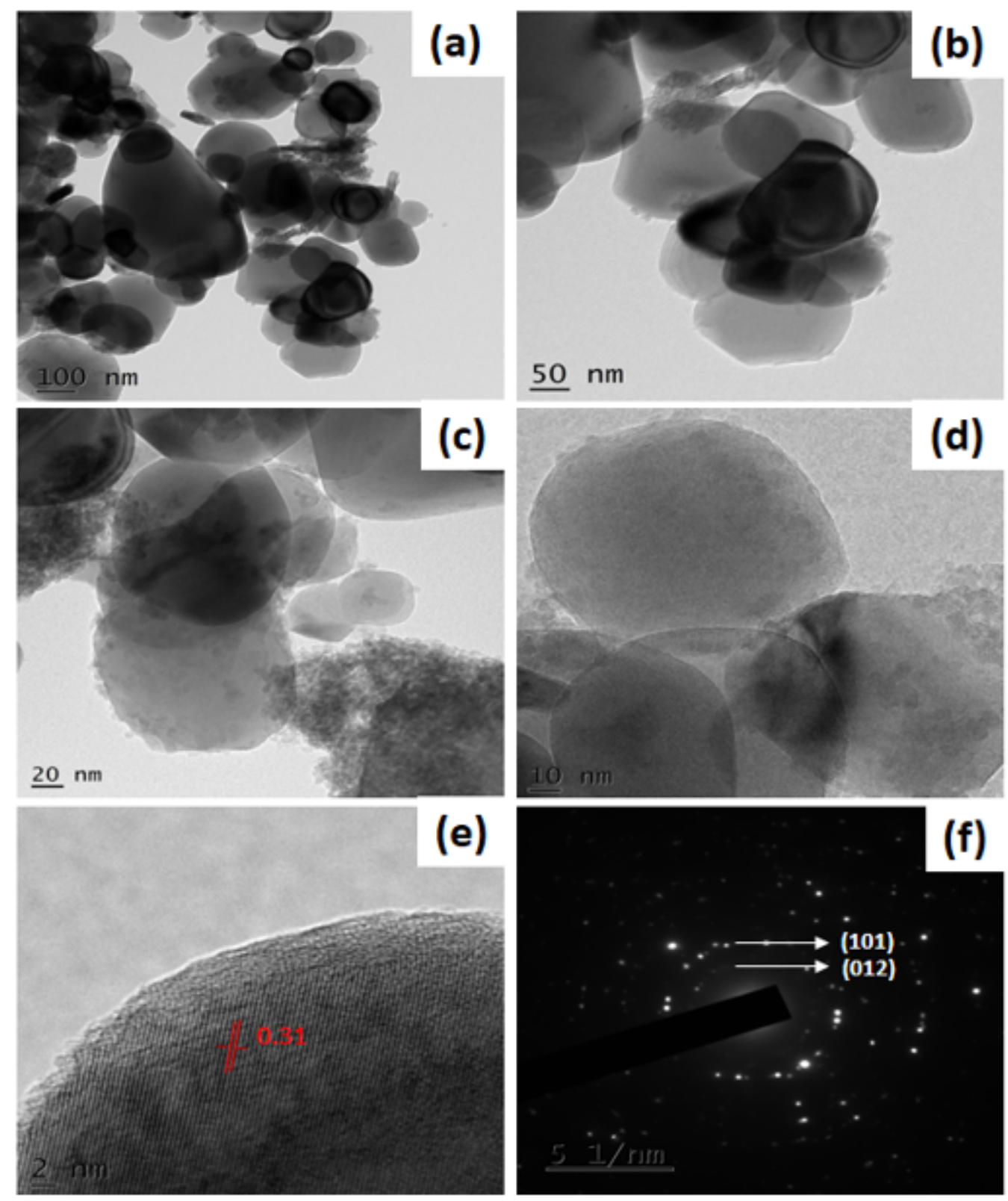

Figure 5

Typical HRTEM images of as-fabricated TiO2/a-Fe2O3 heterostructured composite 

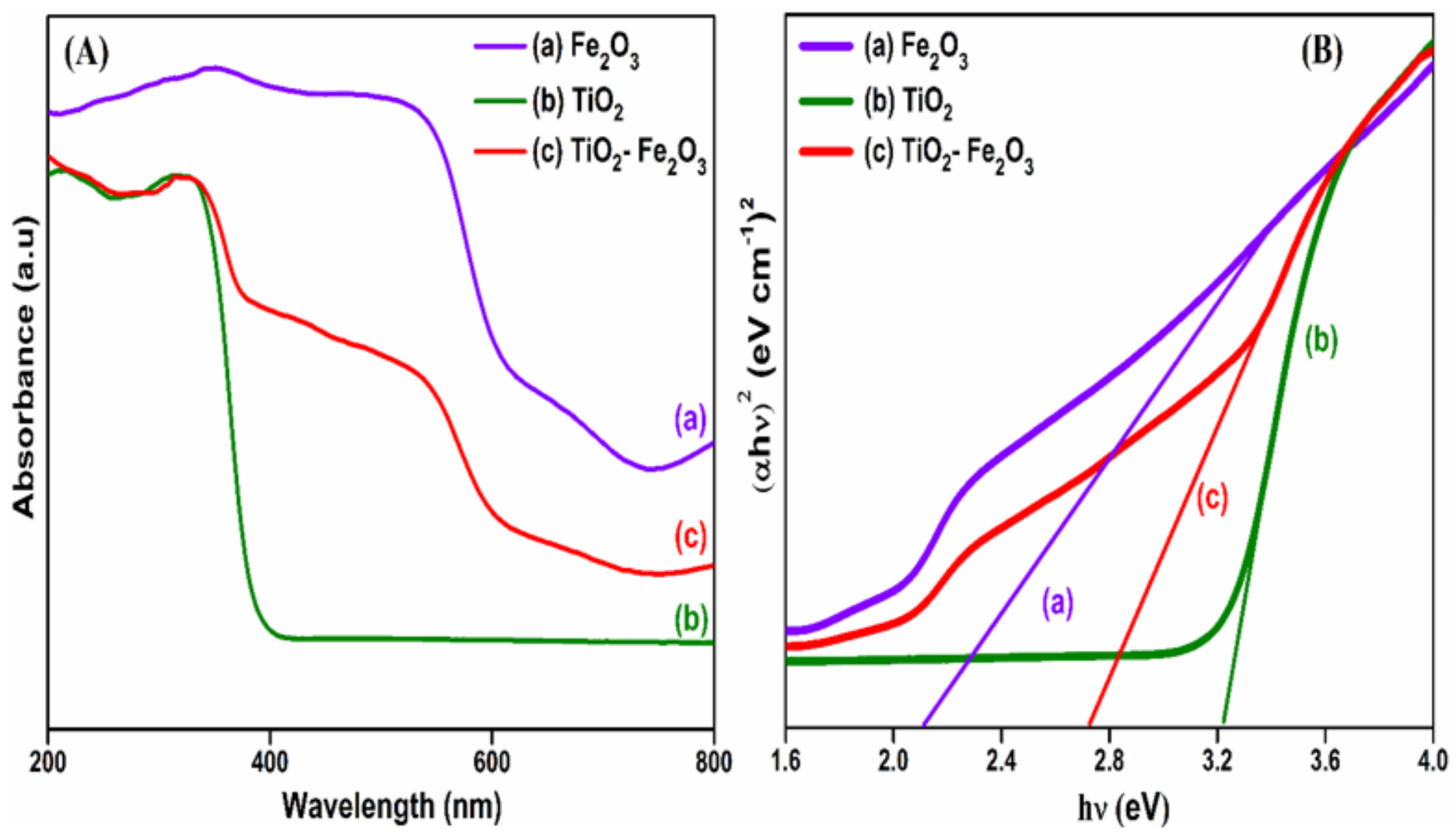

Figure 6

(A) UV-Vis DRS optical absorption spectra (B) relative Tauc plot of as-fabricated (a) pristine TiO2 (b) a-Fe2O3 (c) TiO2/a-Fe2O3 NMs
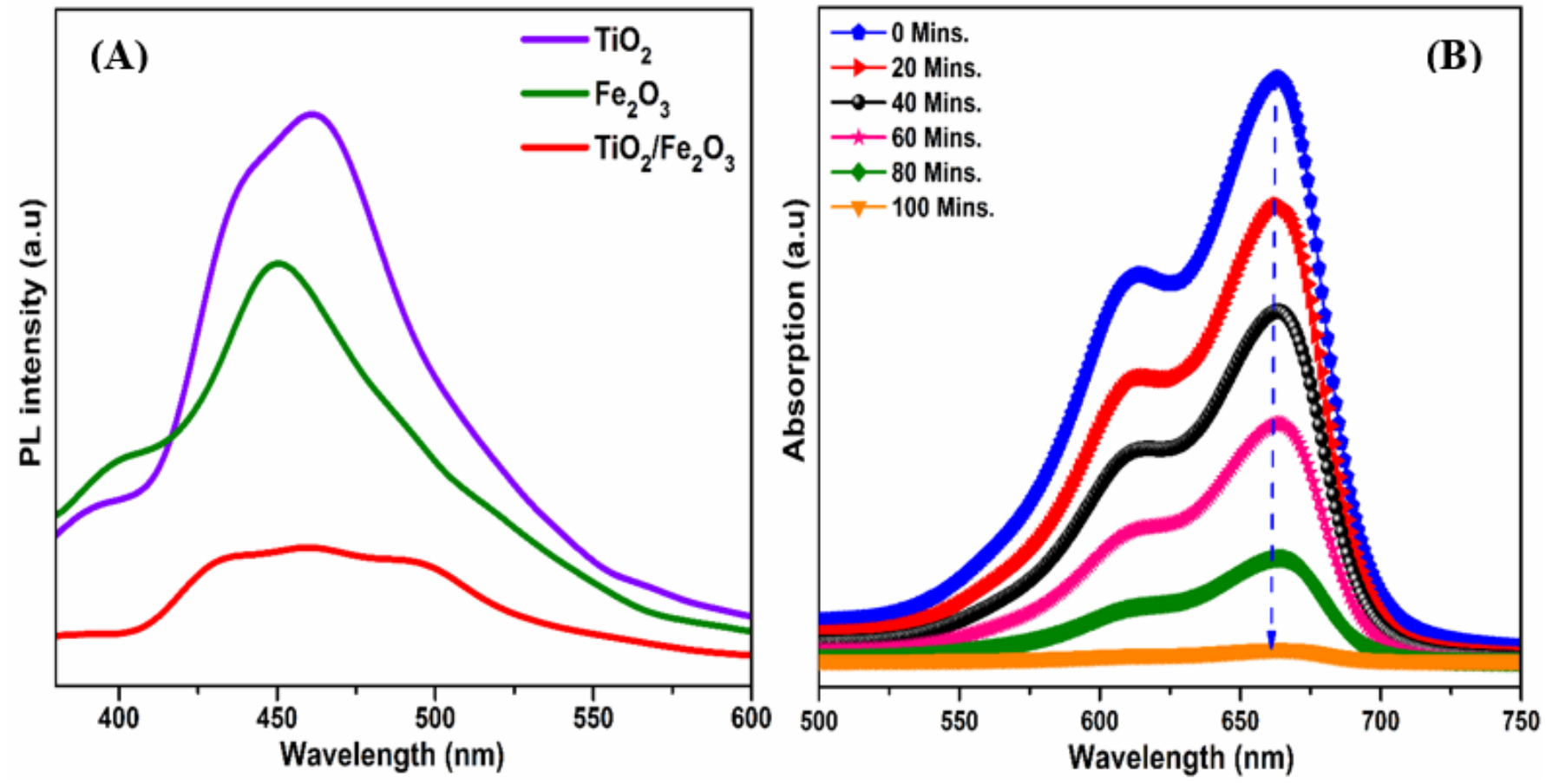

Figure 7 
(A) Room-temperature PL spectra, $\lambda$ ex $330 \mathrm{~nm}$; and Photocatalytic degradation of MB over the TiO2/ a-Fe203 composite catalyst under visible-light exposure
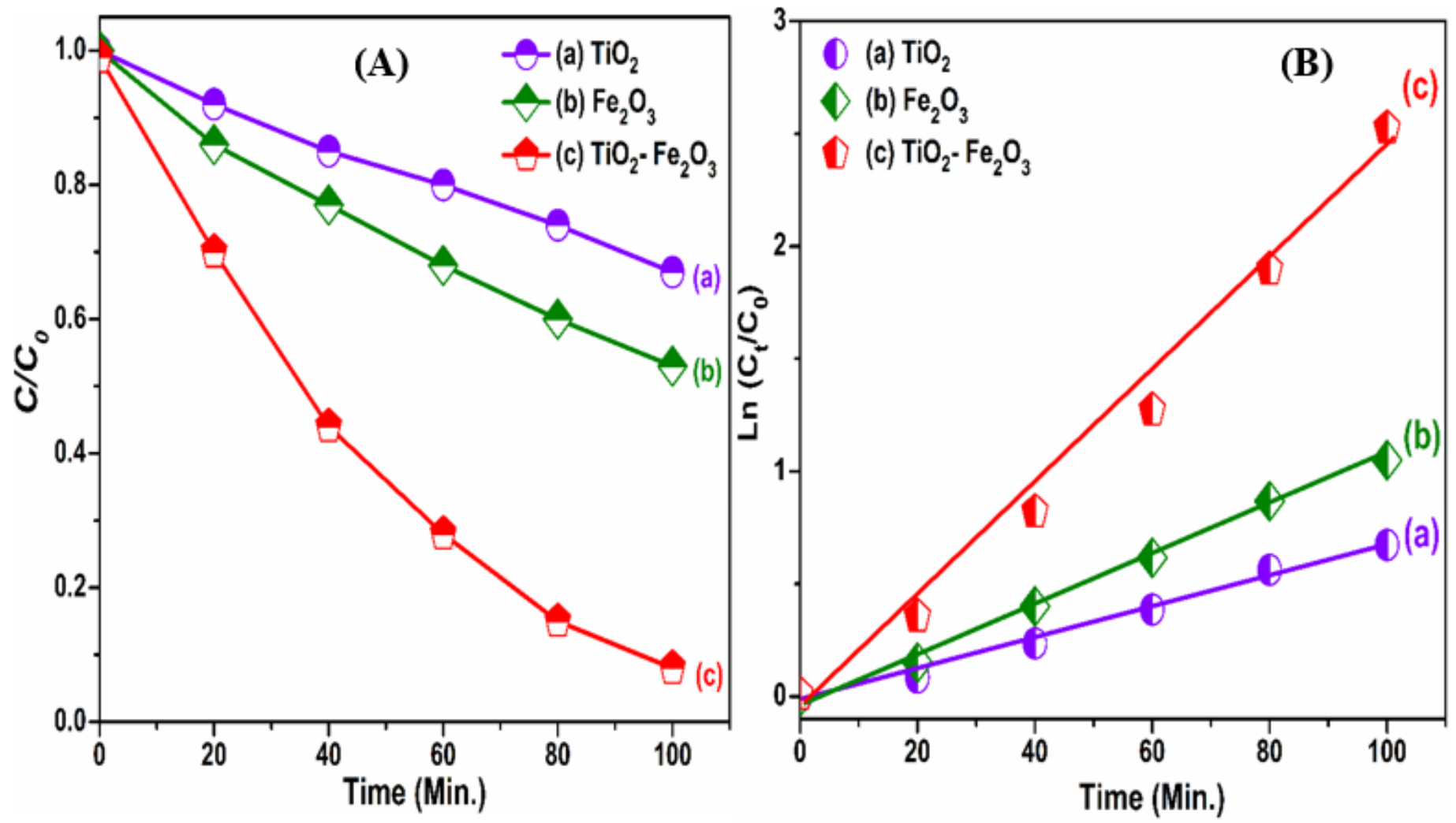

Figure 8

(A) Photodegradation efficiency of MB dye (B) First-order kinetic fitting plots - In (CO/Ct) versus reaction time $t$ for the as-obtained different PCs 

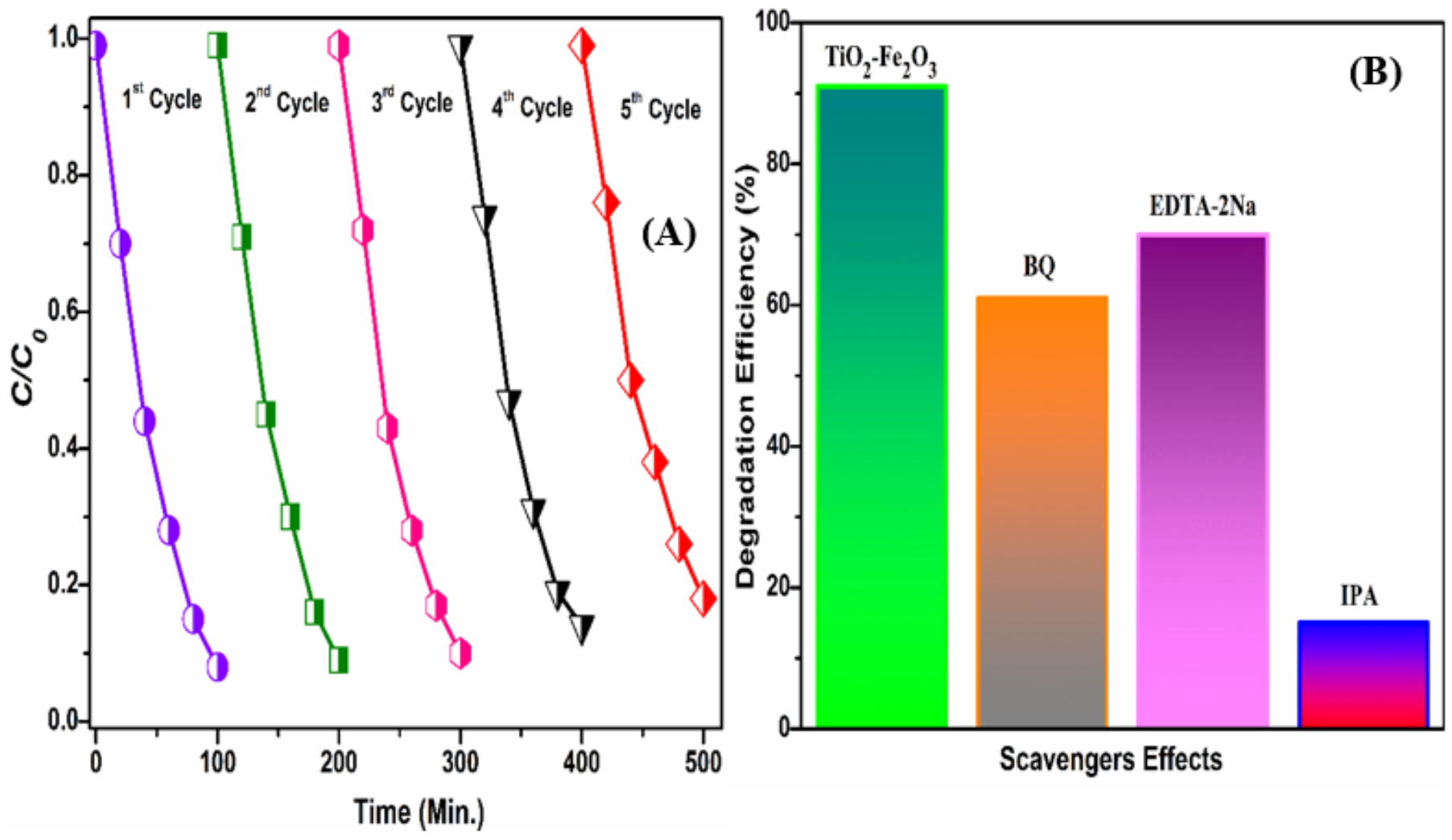

Figure 9

(A) Photocatalytic recycling stability of energetic Ti02/a-Fe2O3 PCs and (B) Photodegradation of MB aqueous dye over as-obtained TiO2/a-Fe2O3 composite catalyst in the existence of dissimilar scavengers
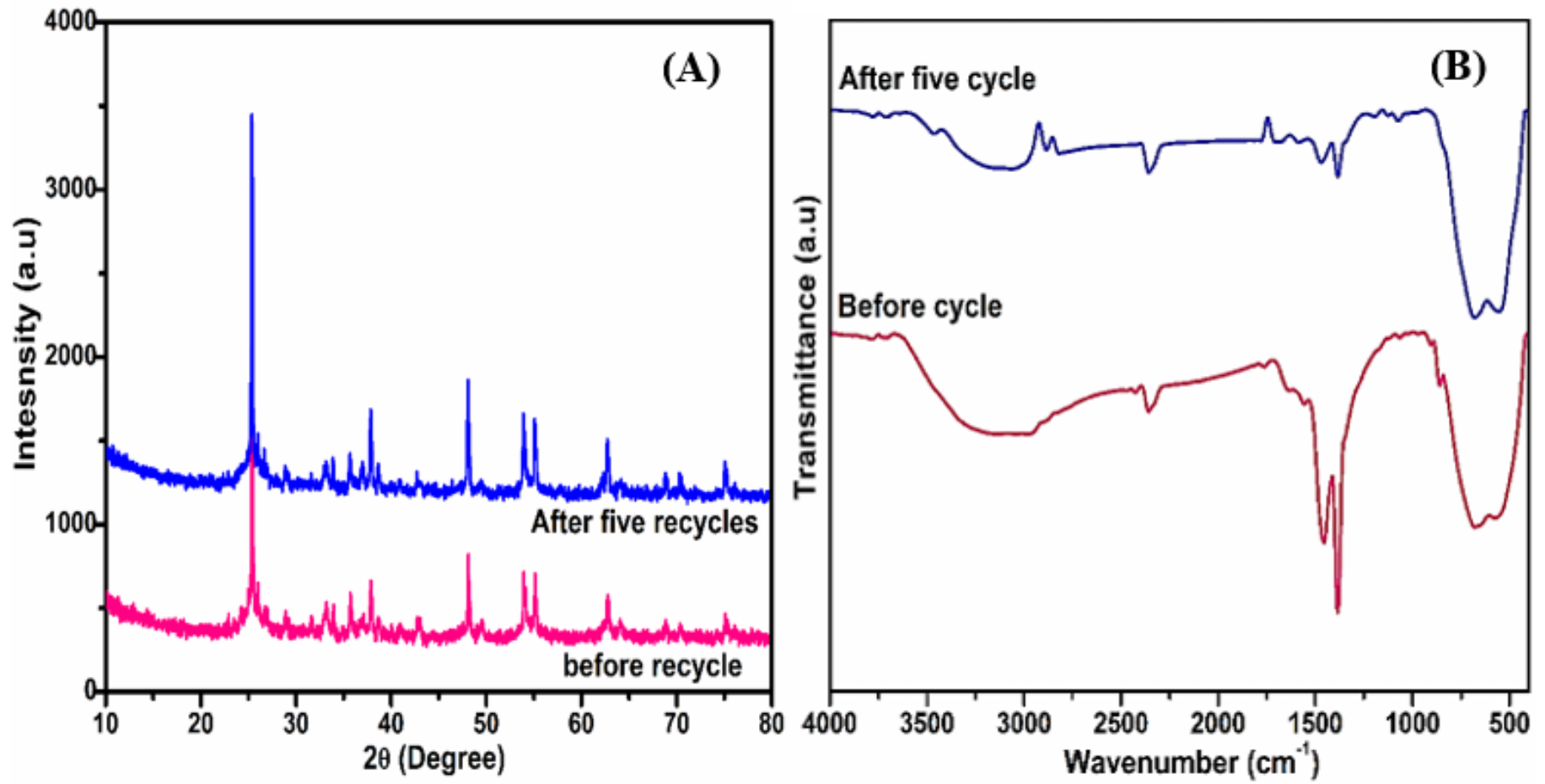

Figure 10 
(A) XRD pattern and (B) FT-IR spectra of TiO2/a-Fe2O3 composite catalyst by before (a) and after (b) recycling process

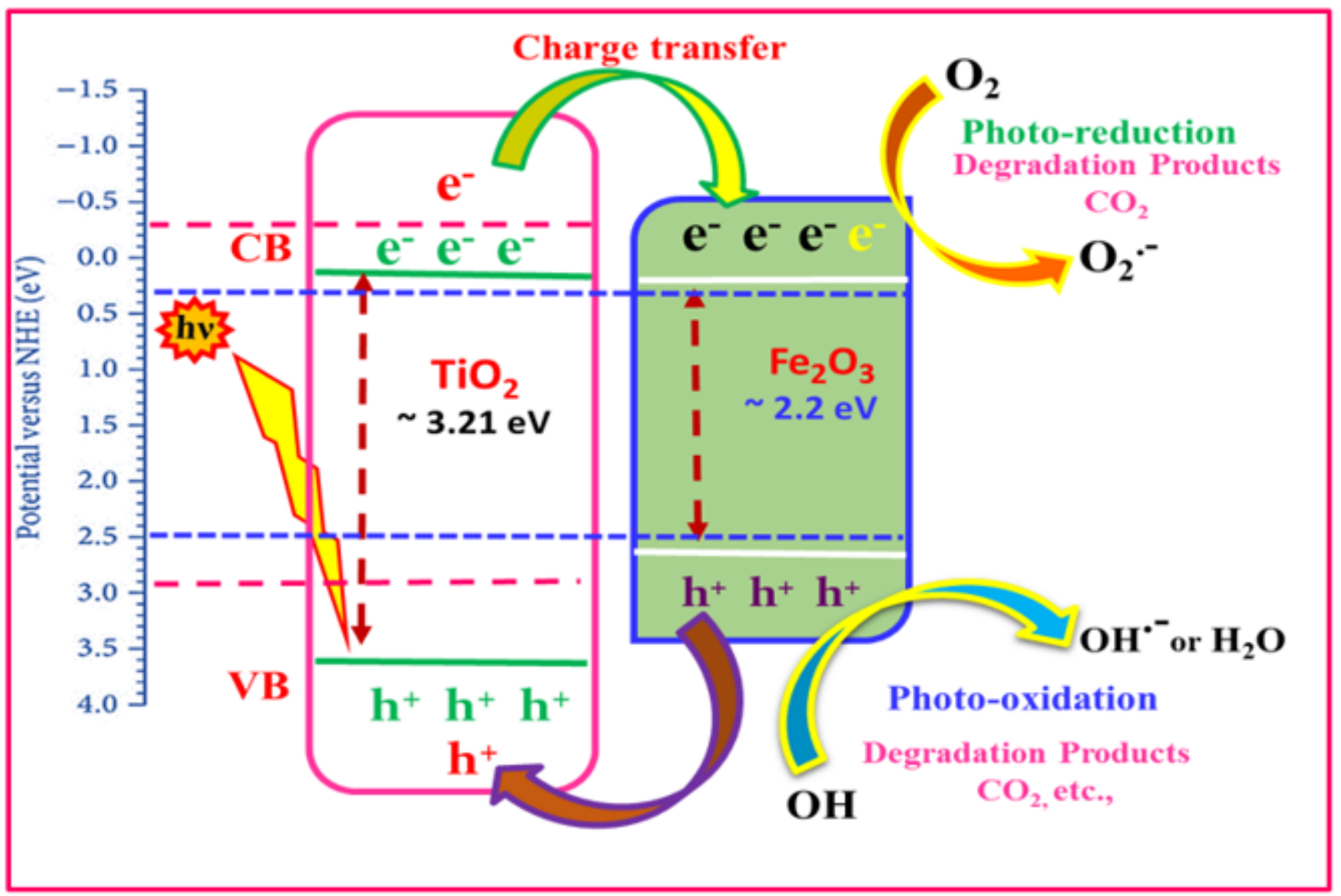

Figure 11

Photocatalytic mechanisms for schematic diagram of TiO2/a-Fe2O3 heterostructure composite catalyst under visible-light exposure 